\title{
MUDANÇAS TECNOLÓGICAS E SEUS IMPACTOS NO PROCESSO DE TRABALHO NA ÁREA DE ANÁLISES CLÍNICAS: CONTRIBUIÇÕES PARA O ENSINO DE CIÊNCIAS
}

\author{
TECHNOLOGICAL CHANGES AND ITS IMPACTS ON THE WORK PROCESS IN \\ CLINICAL ANALYSIS AREA: CONTRIBUTIONS TO SCIENCE TEACHING
}

\author{
Flávia Coelho Ribeiro Mendonça ${ }^{1}$ \\ Maria Beatriz Siqueira Campos de Oliveira ${ }^{2}$ \\ Mônica Mendes Caminha Murito ${ }^{3}$ \\ Marco Antonio Ferreira da Costa
}

\begin{abstract}
RESUMO: O objetivo desse estudo, no campo do ensino de ciências, foi discutir a formação do técnico de nível médio que atua na área de análises clínicas, frente às mudanças tecnológicas no processo de trabalho Os sujeitos da pesquisa trabalhavam em laboratórios clínicos de rotina diagnóstica de três Instituições do município do Rio de Janeiro. Utilizamos como instrumento de coleta de dados, entrevistas com perguntas abertas e fechadas. Como resultados, verificamos que nos setores de bioquímica e uroanálise, todas as técnicas passaram a ser automatizadas, diferentemente do observado nos outros setores em que apenas uma parte das técnicas foi automatizada, com exceção do setor de parasitologia, totalmente manual. Essa pesquisa apontou que apesar de não ter havido impacto no processo de trabalho desta área, a formação do trabalhador deve ser ampliada para atender as tendências futuras das novas tecnologias.
\end{abstract}

Palavras-chave: Educação Profissional. Processo de Trabalho em Saúde. Novas Tecnologias.

ABSTRACT: The aim of this study, in the science teaching field, was to go deeper on the debate of the formation of mid-level technician who works in the area of medical tests, forward to technological changes in the work process. The subjects of the research worked in clinical laboratories of diagnostic routine from three Institutions in the city of Rio de Janeiro. As a data collection instrument, interview with open and closed questions were used. As results, we verified that in the fields of biochemistry and urinalysis, all techniques have become automated, differently from what we have observed in the other sectors in which only some of the techniques had been automated, with the exception of the parasitology sector, fully manual. This research pointed that although there was no impact on the working process of this area, the formation of the worker must be expanded to attend future trends of the news technologies.

Keywords: Professional Education. Work Process in Health. New Technologies.

\footnotetext{
Médica Veterinária. Doutora em Ciências. Professora-pesquisadora da Escola Politécnica de Saúde Joaquim Venâncio- FIOCRUZ. E-mail: flavia.ribeiro@fiocruz.br

2 Biomédica. Doutora em Ciências, IOC/Fiocruz.E-mail: bia.fiocruz@gmail.com

3 Engenheira química. Mestre em Ciências. Professora-pesquisadora da Escola Politécnica de Saúde Joaquim Venâncio- FIOCRUZ. E-mail: monica.murito@fiocruz.br

${ }_{4}$ Engenheiro químico. Doutor em Ciências. Professor-pesquisador da Escola Politécnica de Saúde Joaquim Venâncio-FIOCRUZ.E-mail: marco.costa@fiocruz.br
} 


\section{INTRODUÇÃO}

O trabalho em saúde vem sofrendo mudanças em função do progresso tecnológico, da reorganização dos serviços e das demandas da sociedade, principalmente no que se refere à resolutividade e a qualidade. Para Peduzzi (2003), o campo da saúde apresenta uma complexidade dinâmica, uma vez que intervêm sobre questões relativas à vida e à morte, recortadas, como objetos de intervenção, como saúde e doença. Segundo a autora, o setor saúde possui um trabalho reflexivo, dotado de incertezas e descontinuidade, o que dificulta a normatização das funções técnicas e impossibilita a definição de rígidos critérios econômicos de produção. Contudo, o trabalho em saúde seguiu nos moldes do trabalho industrial, tendo como base organizacional o modelo taylorista-fordista.

No início do século XX, Henry Ford considerou que para que o capitalismo prosperasse seria necessário dotar seus empregados de capacidade de compra e tê-los, futuramente, como clientes. Era a época da "produção em massa", da sociedade integrada pela produção e consumo. A organização, de acordo com Taylor, contemporâneo de Ford, devia basear-se na divisão do trabalho e na repetição da tarefa. A concepção do taylorismo/fordismo acabou por formar operários disciplinados, especializados e cumpridores de ordens. Até o início dos anos 1970, predominou, nos países centrais, o sistema de produção fordista, onde o trabalhador era qualificado para o posto de trabalho que ocupava. As principais características deste modelo são: (a) a produção em série de produtos padronizados; (b) a divisão técnica do trabalho baseada em postos de trabalho encadeados com tarefas simplificadas e repetitivas e com alto grau de prescrição e (c) a rígida separação entre planejamento (concepção) e execução. A educação profissional valorizada era aquela que priorizava o treinamento, a execução e o aperfeiçoamento das tarefas com otimização do tempo (PINTO, 2007).

No trabalho desenvolvido por Teixeira (2003), em laboratórios de pesquisa e desenvolvimento tecnológico em saúde, a autora constatou que no laboratório de desenvolvimento de vacinas pesquisado não existia rodízio ou escala na rotina do laboratório, as tarefas eram distribuídas entre os funcionários, cabendo a cada um deles uma etapa da totalidade das atividades. Os técnicos de nível médio e superior 

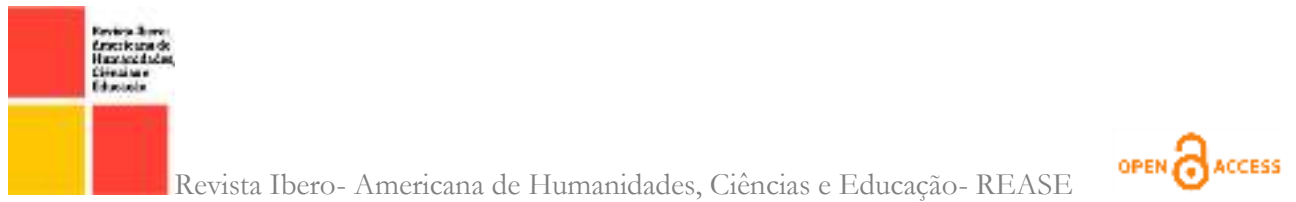

encarregavam-se das soluções e meios comuns, enquanto os pesquisadores dedicavam-se à preparação dos itens específicos a cada projeto, seguindo o modelo taylorista-fordista.

No final do século XX, surgiu o modelo produtivo, denominado "especialização flexível”, baseado principalmente na substituição das linhas de montagem tradicionais por "ilhas de produção" fundamentadas no trabalho cooperativo, na utilização de tecnologia de base microeletrônica e na inexistência de uma separação rígida entre concepção e execução. Ribeiro (2005) aponta que essa nova configuração do mundo de trabalho, principalmente no campo da saúde, tem exigido um novo perfil profissional sintonizado com competências que ultrapassam a excelência técnica e incluem as dimensões socioeconômicas e culturais para enfrentar os problemas de saúde da população, nas esferas individual e coletiva, e não apenas na hospitalar.

As transformações que o mundo do trabalho vem sofrendo devido às mudanças ocorridas nos processos laborais, tanto organizacionais como tecnológicas, apontam como consequências uma redefinição na divisão do trabalho, gerando formas de polivalência dos profissionais, e a emergência de novos requisitos para a formação dos trabalhadores.

Nos primeiros anos do século XXI foi realizada uma pesquisa em uma escola técnica da área da saúde do município do Rio de Janeiro, cujos resultados apontaram para a modernização tecnológica e a implantação da automação como uma realidade presente nos processos de trabalho na área de biodiagnóstico (OLIVEIRA, 2005). Os resultados mostraram que a justificativa para a intensa implementação da automação neste setor ocorreu principalmente pela busca da melhoria da qualidade, precisão e confiabilidade dos exames de análises clínicas. Além disso, a incorporação da automação no processo produtivo visou a atender as bases de desenvolvimento do modelo flexível de organização do processo de trabalho em saúde. Entretanto, a pesquisa apontou que essa automação não requereria um técnico que soubesse apenas “apertar botões”, precisava sim um profissional com senso crítico capaz de analisar todo processo de trabalho, e por meio de um conhecimento teórico fundamentado, conseguisse avaliar os resultados. 

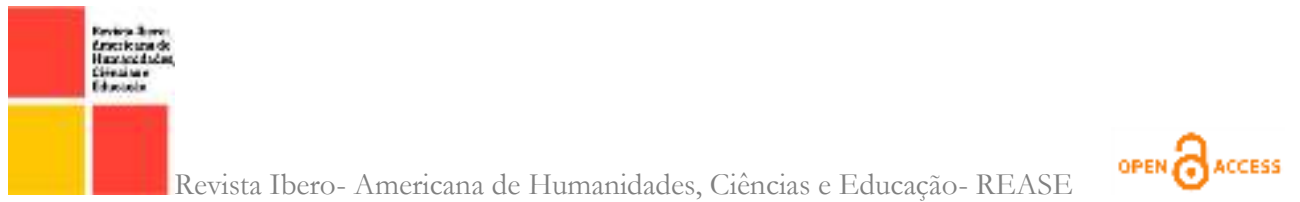

Em 200I, foi realizado por Dias Netto um estudo no Rio de Janeiro, com funcionários de Patologia Clínica e de Anatomia Patológica de um hospital federal do e de um serviço de Patologia Clínica de um instituto de pesquisa. Os resultados mostraram que apenas $14 \%$ das técnicas eram executadas manualmente, I8\% das tarefas estavam totalmente automatizadas e $68 \%$ eram consideradas como função mista, isto é, possuíam atividades executadas manualmente e através de sistemas automáticos. $O$ primeiro resultado diz respeito ao Setor de Parasitologia, no qual era impossível realizar uma implementação tecnológica devido às técnicas de análises utilizadas naquela época. O relato de um profissional que trabalhava no Setor de Bioquímica exprimiu as mudanças de função do técnico frente aos impactos gerados pela implementação da automação no seu setor, explicando que, inicialmente, todas as técnicas eram executadas em bancadas, e que depois foram sendo substituídas pela máquina, cabendo a ele apenas preparar os reagentes, calibrar os aparelhos e observar os resultados (DIAS NETTO, 200I).

Os resultados da pesquisa de Dias Netto (200I) também apontaram que $46 \%$ dos 1688 técnicos fizeram curso de informática, refletindo a importância que este conhecimento exerce no cenário atual do mundo do trabalho, e $26 \%$ estudaram inglês e reconhecem a importância deste curso, uma vez que a maioria das máquinas tem catálogos e especificações nesse idioma. Os laboratórios pesquisados passaram, também, por reformas que visavam a integrar diversas etapas desse processo, agilizando o fluxo e a comunicação intersetorial. O laboratório se tornou um grande salão, em que os setores não são separados por divisórias físicas, gerando a possibilidade de reformulação do espaço de acordo com a necessidade.

Com os resultados destes trabalhos, pode-se afirmar que o setor laboratorial passou por um período de adaptação à tendência de flexibilização da organização de seus processos produtivos; que este setor é um grande consumidor de tecnologia; e sua força de trabalho técnica, ainda que de forma heterogênea, caminha para um upgrade profissional e uma organização polivalente do trabalho (DIAS NETTO, 2oor; OLIVEIRA, 2005). 

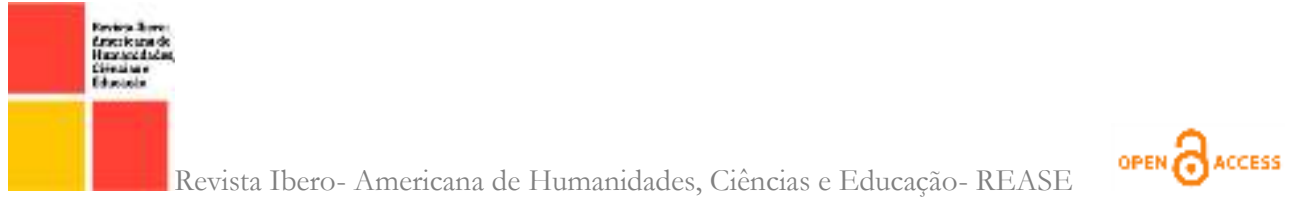

Os Referenciais Curriculares Nacionais para a Educação Profissional de Nível Técnico (PINHÃO e MARTINS, 2012; BRASIL, 200o), para a área da Saúde, apresentam como competências gerais, conforme descrito neste documento, a identificação dos determinantes e condicionantes do processo saúde-doença; da estrutura e organização do sistema de saúde vigente; das funções e responsabilidades dos membros da equipe de trabalho e das rotinas; protocolos de trabalho, instalações e equipamentos. Além disso, a aplicação de normas de biossegurança; de princípios éticos; de princípios e normas de higiene e saúde pessoal e ambiental; da legislação referente aos direitos do usuário; e de princípios ergonômicos na realização do trabalho, estão também entre as competências desta área.

Nesse contexto, onde o panorama do processo de trabalho em saúde apresenta uma influência direta do mundo do trabalho, a educação profissional de Ensino Médio na área da saúde precisa estar constantemente revendo as mudanças organizacionais e tecnológicas para atualizar os seus currículos, de modo a formar um trabalhador crítico com qualificação técnica e consciente do seu papel enquanto cidadão (MONTEGUTI e

DIEHL, 2016). Dessa forma, esta pesquisa visa a aprofundar o debate sobre a formação do técnico de nível médio que atua na área de biodiagnóstico em saúde, frente às mudanças tecnológicas no processo de trabalho.

\section{METODOLOGIA}

A pesquisa, com abordagem qualitativa (COSTA; COSTA, 2020), ocorreu no período de 2009-20II em laboratórios de análises clínicas do município do Rio de Janeiro. Foram pesquisados três laboratórios, sendo um de uma instituição pública de grande porte (A) e dois laboratórios privados, um também de grande porte (B) e um de pequeno porte (C). Essa pesquisa foi submetida e aprovada pelo Comitê de Ética em Pesquisa (CEP) da Escola Politécnica de Saúde Joaquim Venâncio / Fiocruz, sob o número CAAE - ool8.0.408.000-9, protocolo 2009/0075.

A seleção dos locais estudados obedeceu aos seguintes critérios de inclusão: nível de complexidade e diversificação dos serviços executados em cada laboratório; participação de trabalhadores na função de técnicos; natureza jurídica da organização a 

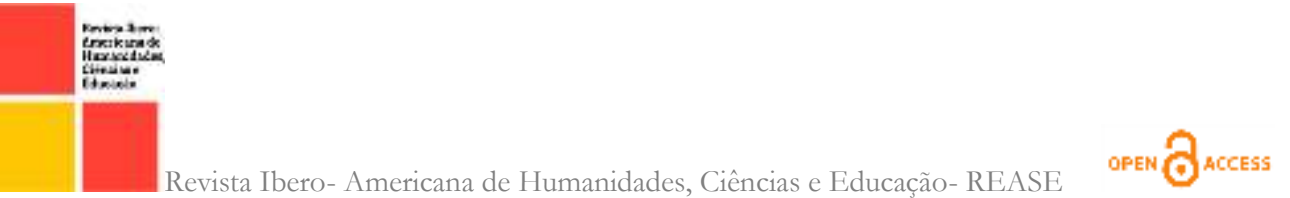

que está vinculada; tempo de funcionamento; grau de expansão nos últimos dois anos (dinâmica crescimento) e interesse em participar da pesquisa. Além disso, todos os laboratórios pesquisados realizavam atividades de rotina em diagnóstico clínico que incluíssem pelo menos uma das atividades: coleta, patologia clínica, parasitologia, histotécnica, bacteriologia, micologia e diagnóstico molecular.

A pesquisa foi realizada de maneira que fossem representados todos os setores acima citados. O sigilo de participação das instituições pesquisadas e dos sujeitos entrevistados foi garantido, uma vez que não foram citados os nomes desses.

Os sujeitos pesquisados compreenderam: técnicos que atuam nos setores de Patologia Clínica, Coleta, Parasitologia, Anatomia Patológica (histotécnica), Bacteriologia, Micologia e Diagnóstico Molecular. A escolha desses sujeitos se deu por esses representarem o trabalhador que está sendo admitido pelos laboratórios de análises clínicas, tanto de instituições públicas quanto privadas. A amostra agregou 18 técnicos $(n=18)$ com diferentes vínculos empregatícios que atuavam em diferentes setores.

O levantamento de informações sobre a dinâmica do processo de trabalho na área de análises clínicas, o perfil dos trabalhadores que vêm sendo admitidos e o comportamento do mundo do trabalho foi realizado por meio de entrevista semiestruturada, feita separadamente e marcada com antecedência, de acordo com a disponibilidade do entrevistado. As entrevistas foram individuais e realizadas pelo próprio autor. Todos os entrevistados assinaram o Termo de Consentimento Livre e Esclarecido (TCLE). Com o objetivo de resguardar o anonimato dos entrevistados, procurou-se criar uma codificação, utilizando um registro alfanumérico, a fim de preservar a liberdade de opinião e a ética do trabalho (LUDKE; ANDRÉ, 1986). O roteiro das entrevistas apresentava perguntas fechadas e abertas, possibilitando aos sujeitos a oportunidade de se pronunciar sobre o tema de estudo.

$O$ roteiro de entrevista semiestruturada foi elencado em blocos de questões referentes à formação, à trajetória profissional, à situação do trabalho, dos técnicos dos laboratórios e ainda, às técnicas de diagnóstico realizadas. A entrevista semiestruturada oferece ao pesquisador maior flexibilidade, já que permite intervenções de acordo com o seu desenvolvimento. 

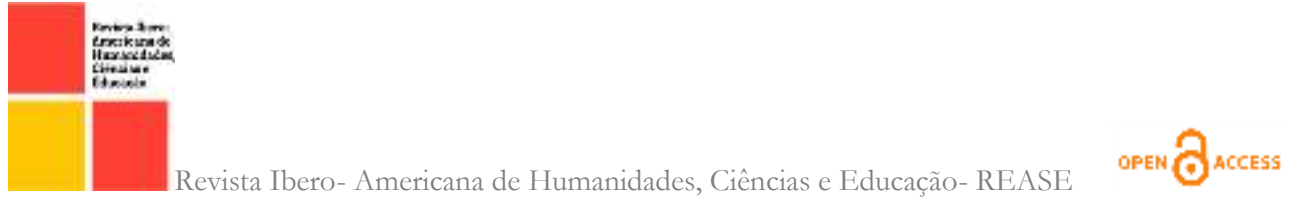

Alguns passos foram seguidos no tratamento dos dados: ordenação dos dados, transcrição da gravação e a classificação dos dados. Os resultados tiveram seus conteúdos analisados, segundo Turato (2003). Foram identificadas quatro categorias, utilizando os critérios de repetição e relevância: formação profissional, qualificação para o trabalho, processo de trabalho e novas tecnologias. De acordo com Minayo (2000), esse momento de categorização integra uma leitura chamada "flutuante", em que se procura apreender as ideias centrais das entrevistas e seus momentos-chave.

A análise foi feita à luz do referencial teórico, adotando os postulados da teoria crítica, à medida que segue os princípios da pedagogia marxista (MANACORDA, 200o). Utilizou-se como referência a construção de modelo de educação politécnica em contraposição à educação profissional de nível técnico voltado apenas para o mercado de trabalho. A escolha deste paradigma se deu pela convicção de que a construção do conhecimento se processa pela subjetivação da realidade, em um processo de transformação da objetivação.

\section{RESULTADOS}

Os resultados foram analisados levando-se em consideração as peculiaridades de cada laboratório. Para facilitar o entendimento, a análise das entrevistas dos gestores e dos técnicos foi realizada separadamente. Os setores estudados foram: Anatomia Patológica, Bioquímica, Hematologia, Coleta, Imunologia, Parasitologia, Uroanálise, Micologia e Virologia, das três instituições.

Os dados no Quadro I, relativo aos técnicos, apresentam os códigos dos sujeitos da pesquisa e a diversidade de setores da área de Análises Clínicas. O número de profissionais que atua como técnicos nos laboratórios pesquisados é de 54 na Instituição A, com média de 5 técnicos por setor, I9 na Instituição B e 4 na C. Dentre esses, foram entrevistados 18 técnicos. A carga horária semanal de trabalho dos técnicos da Instituição A é de 40 horas, enquanto todos das Instituições B e C são funcionários com carteira assinada para a realização de trabalho com 36 a 44 horas semanais. 
Quadro I - Códigos relativos aos técnicos de laboratório pesquisados

\begin{tabular}{l|l|}
\hline \multicolumn{1}{|c|}{ Sujeitos da Pesquisa } & \\
\hline$T_{1}$ & Micologia \\
\hline$T_{2}$ & Imunologia \\
\hline$T_{3}$ & Coleta de Sangue \\
\hline$T_{4}$ & Anatomia Patológica \\
\hline$T_{5}$ & Parasitologia \\
\hline$T_{6}$ & Uroanálise \\
\hline$T_{7}$ & Virologia \\
\hline$T_{8}$ & Bioquímica \\
\hline$T_{9}$ & Hematologia \\
\hline$T_{10}$ & Uroanálise \\
\hline$T_{11}$ & Bioquímica \\
\hline$T_{12}$ & Parasitologia \\
\hline$T_{13}$ & Microbiologia \\
\hline$T_{14}$ & Distribuição de material \\
\hline$T_{15}$ & Hematologia \\
\hline$T_{16}$ & Todos os Setores \\
\hline$T_{17}$ & Todos os setores \\
\hline$T_{18}$ & Todos os setores \\
\hline
\end{tabular}

Fonte: Elaborado pelos autores

E em relação à categoria formação profissional, os resultados apontaram que o pré-requisito requerido para a admissão desse profissional é a formação técnica na área de laboratório (Análises Clínicas, Biodiagnóstico, Patologia Clínica ou similar). A formação dos técnicos nos laboratórios pesquisados foi predominantemente em Análises Clínicas $(n=15)$, mas também havia técnicos em Biologia Parasitária e em Biotecnologia.

Dentro desse contexto, Teixeira e Murito (2007), em estudo realizado em laboratórios de pesquisa da área da saúde, concluíram que esses locais funcionam como uma espécie viva e atuante de como um processo de trabalho pode comportar uma forte e permanente dimensão qualificante. Nessa pesquisa, as autoras observaram que os profissionais aprendem novas técnicas seja por rodízio das atividades ou por implantação de novas tecnologias. Abrahão (2005), diz que os conhecimentos são adquiridos no próprio espaço de trabalho e de acordo com a estrutura dos processos internos a cada setor e com a sua organização. A construção do conhecimento, muitas vezes se dá através de uma "educação não formal”, onde os espaços educativos 

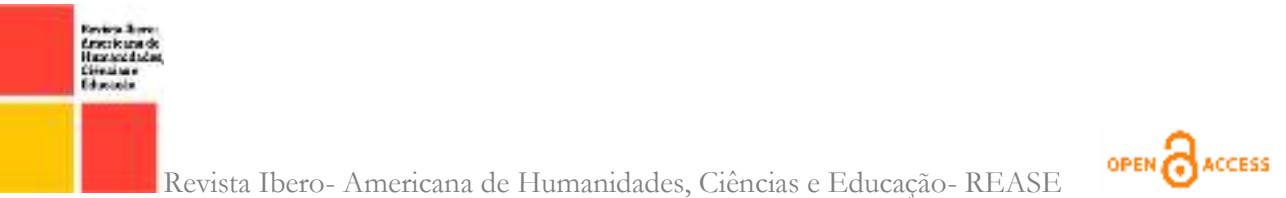

localizam-se em territórios que acompanham a trajetória de vida dos indivíduos, no caso dos trabalhadores (MURITO, 2007). Segundo Loch (2015), os serviços de saúde podem ser importantes espaços para a aprendizagem significativa desses conhecimentos.

Por outro lado, a presente pesquisa apontou que todos os técnicos, com exceção de um $\left(\mathrm{T}_{3}\right)$ da Instituição A, apresentavam nível superior em um dos cursos: Biologia, Farmácia, Enfermagem ou Física, sendo que quatro ( $\mathrm{T}_{\mathrm{I}}, \mathrm{T}_{4}, \mathrm{~T}_{6}$ e $\mathrm{T}_{7}$ ), além da graduação, possuíam também especialização latu sensu na área de Biodiagnóstico. Entretanto, nas Instituições $\mathrm{B}$ e $\mathrm{C}$ nenhum dos técnicos entrevistados possuía nível superior, apenas o curso técnico. Acredita-se que isso se deve, principalmente, porque na Instituição A, a contratação se dá através de concurso público realizado para serem servidores, possibilitado muitas vezes pela pontuação da titulação.

A formação de quase todos os técnicos entrevistados foi considerada fraca na autoavaliação, especialmente devido às poucas aulas práticas, prejudicando-os quando da realização do estágio curricular. Seguem alguns comentários deles:

"Tive dificuldade para a realização do estágio porque o meu curso teve pouca aula prática e o que aprendi realmente foi no dia a dia do meu trabalho." (Тiо)

"Aprendi mesmo no estágio, foi o que me deu o suporte para que hoje eu pudesse estar aqui." ( $\left.\mathrm{T}_{14}\right)$

"Para fazer o que faço hoje, precisei de mais." (Ti2)

"Somos obrigados a estudar ou pesquisar em livros para realizar o trabalho." (T13)

“Foi o que me deu base, a metade do que aprendi de laboratório foi no estágio.” (Ti6)

Entretanto, $\mathrm{T}_{2}$ informou que, apesar de ter tido poucas aulas práticas, a teoria deu embasamento, e $\mathrm{T}_{\mathrm{I}}$, diferentemente dos outros técnicos, afirmou: "O meu curso técnico, realizado na Escola Federal de Química, foi muito bom, até melhor do que muita faculdade, vivenciei bastante a teoria e a prática". Poucos técnicos como Ti relataram terem obtido base na formação técnica.

Esses resultados reforçam a teoria de Peduzzi (2003), na qual a autora conclui que um novo ambiente tecnológico necessita de uma formação sólida básica que inclua importantes aspectos, além do domínio das técnicas, tais como a capacidade de trabalhar em equipe, iniciativa e competência para avaliar os resultados e solucionar os problemas 

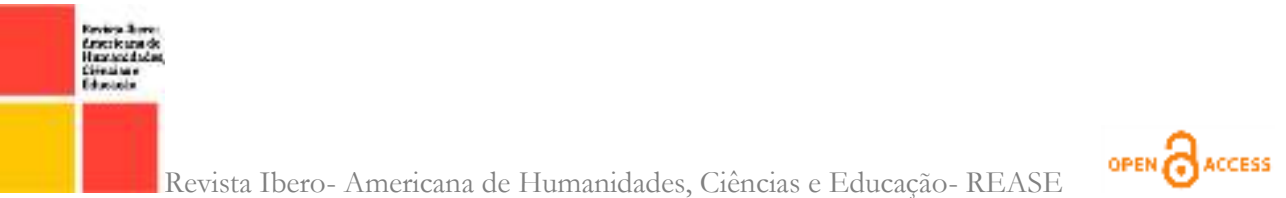

que surgem durante o processo. Os trabalhadores reconhecem a importância de uma formação sólida, para uma maior compreensão do seu processo de trabalho em uma dimensão mais ampla, que vai além da dimensão técnica (MURITO, 2007).

Muitos dos técnicos entrevistados se queixaram também da falta de atualização no curso: "Os cursos não se atualizam a cada ano, principalmente nas disciplinas que sofrem constante mudança."

O Catálogo Nacional de Cursos do Ministério da Educação (BRASIL, 2020), cita que o currículo do Técnico em Análises Clínicas, com o mínimo de 1.20o horas, deve compreender conteúdos teóricos e práticos nas áreas de Parasitologia, Microbiologia Médica, Imunologia, Hematologia, Bioquímica, Biologia Molecular, toxicologia, de hormônios, líquidos corporais. O técnico formado nesta área deve compor as equipes multidisciplinares da área da Saúde, na investigação e implantação de novas tecnologias biomédicas relacionadas às análises clínicas. É fundamental que o técnico em análises clínicas para a sua atuação profissional tenha conhecimentos das políticas públicas de saúde e compreenda a sua atuação frente às diretrizes e princípios do Sistema Único de Saúde (SUS).

Como locais de atuação para esse técnico o catálogo indica laboratórios de análises e de diagnósticos médicos em hospitais, clínicas, Unidades básicas de saúde (UBS), unidades de Pronto Atendimentos (UPAS); hemocentros laboratórios de diagnósticos médicos humanos e veterinários, laboratórios de toxicologia, laboratórios de pesquisa e ensino biomédico e laboratórios de controle de qualidade em saúde e laboratórios de microbiologia de alimentos (BRASIL, 2020). Nesse aspecto as três instituições ( $\mathrm{A}, \mathrm{B}$ e $\mathrm{C}$ ) apresentam o perfil listado acima, entretanto, o técnico $\mathrm{T}_{\mathrm{I}}$ apresenta uma peculiaridade na relação formação/atuação.

$\mathrm{Na}$ segunda categoria destacada, qualificação profissional, os resultados apontaram um descompasso entre formação e atuação profissional. Segundo TI, o curso técnico de laboratório foi muito abrangente e o seu trabalho atual muito específico.

“... Isso é um procedimento padrão aqui, os estagiários sempre passam por esse curso que é oferecido pelo Curso Técnico de Biologia Parasitária [...] então eu fiz a disciplina do curso 

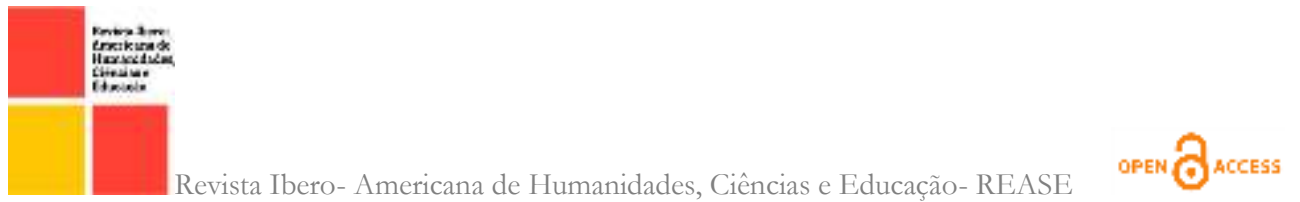

técnico e fiz a disciplina a nível de pós-graduação que é oferecido pelo doutor X da Micologia Médica.” (TI)

Quando perguntado sobre a realização periódica de cursos de qualificação, o mesmo técnico respondeu:

“... Todo ano alguém passa por algum curso... esse ano um colega já foi pra Miami, outro colega já foi ao Peru e eu vou participar agora do curso de atualização em micoses sistêmicas $e$ oportunistas...” (TI

$\mathrm{Na}$ fala do técnico Ti observa-se que seu trabalho é diferenciado da maioria dos laboratórios de análises clínicas, isto porque a Instituição A é um centro de referência em vários setores da área da Saúde, ao mesmo tempo em que é um hospital que presta serviços de diagnóstico para a população. Observa-se nas respostas de Ti que ele é uma exceção, pois sua qualificação e atuação são bem diferentes da maioria dos técnicos que trabalham na área de diagnóstico laboratorial. Isso se deve principalmente ao fato de que laboratórios de pesquisa com ênfase em desenvolvimento tecnológico precisam ter o conhecimento aprofundado da sua área específica, todas as atividades padronizadas (rastreabilidade e repetibilidade) bem como o domínio dos materiais empregados, dos equipamentos, das soluções e das técnicas selecionadas (TEIXEIRA; MURITO, 2007).

Em relação à Biossegurança, isso fica ainda mais evidenciado. $O$ curso de Biossegurança na Instituição A é obrigatório, logo, todos os técnicos dessa instituição fazem periodicamente o referido curso. Eles adquirem conhecimento sobre segurança química e biológica, descarte de material e impacto ambiental, equipamentos de proteção coletiva e individual e vários outros aspectos importantes para quem trabalha em áreas insalubres, como é o caso dos laboratórios da área da saúde.

$\mathrm{Na}$ Instituição $\mathrm{B}$, os técnicos não fazem o curso de Biossegurança, mas recebem regularmente treinamento nessa área, sendo que quatro técnicos já fizeram esse curso. $\mathrm{Na}$ Instituição $\mathrm{C}$ apenas um técnico (Ti6) fez curso de Biossegurança, mas nessa Instituição nenhum técnico é incentivado a fazê-lo periodicamente. Mesmo assim, a maioria $(n=15)$ dos funcionários entrevistados foi alertada quanto aos riscos físicos, químicos e biológicos quando chegaram ao laboratório e, ainda, para realizarem suas atividades nos setores específicos. 

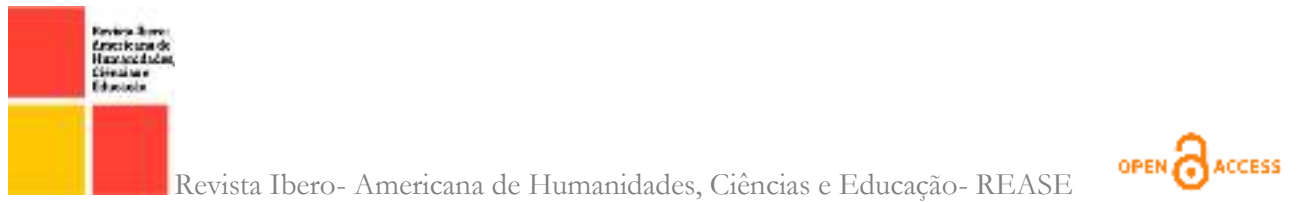

O técnico Ti3, que trabalha há 34 anos como técnico de laboratório, destes 24 anos na Instituição C, quando perguntado se foi alertado sobre as áreas insalubres, doenças ocupacionais, segurança química ou biológica e impacto sobre o meio ambiente por descarte de material, ele respondeu:

"Não, depois que nós viemos para cá as coisas mudaram nesse sentido aí, mas antes ninguém passava nada não, até porque antes não existia muito dessas coisas." ( $\left.\mathrm{T}_{13}\right)$

Ferretti (2004) ressalta que o enfoque da qualificação como relação social, deve incorporar a análise das relações entre a qualificação do trabalhador e as demandas da inovação tecnológica. Baseado nesta afirmativa questiona-se como a formação do Técnico de Análises Clínicas, principalmente dos que precisam dar conta de uma gama de atividades técnicas, relaciona-se com as necessidades qualificacionais exigidas pelas “inovações tecnológicas” e a dinâmica do setor saúde.

Para realizar um trabalho de qualidade, na opinião de todos os técnicos entrevistados, deve existir postura profissional, incluindo comprometimento e responsabilidade, o profissional deve estar sempre se atualizando, saber trabalhar em equipe, ter atenção e conhecimento teórico-prático, além de possuir material e equipamento adequados. Neste novo contexto profissional, os próprios técnicos apontam para o que Bianchetti, em 20or, já havia concluído, que é a valorização não só das habilidades físicas, mas principalmente das qualificações mentais e das capacidades de abstração.

Em relação à categoria processo de trabalho, o técnico de nível médio se depara com modificações organizacionais e tecnológicas na sua área. Esse processo deve estar inserido em um contexto social, político e econômico (VELOSO; PAIXÃO, 2013). Para Peduzzi (2003), as novas formas organizacionais de constante inovação tecnológica requerem o aprofundamento vertical do conhecimento especializado, o que eleva a importância da realização de cursos de atualização na área pelos técnicos. Isso é reforçado pela fala de $\mathrm{T}_{2}$, em que a técnica aponta uma lacuna entre o final do curso técnico e seu trabalho atual. A mesma autora enfatiza que a constante inovação tecnológica fez com que houvesse um descompasso com relação ao que aprendeu na escola, principalmente as técnicas clássicas de bancada e os novos equipamentos 

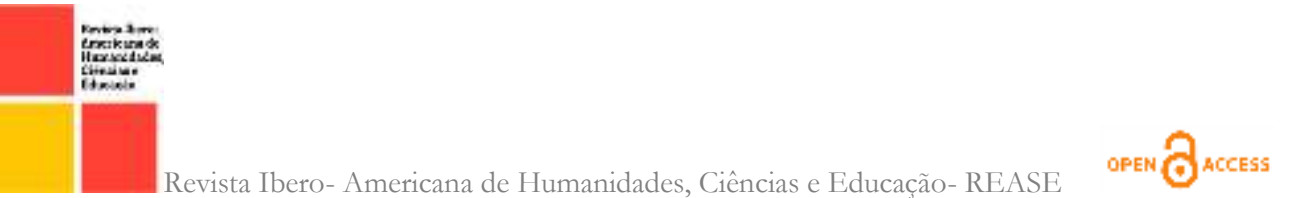

utilizados no setor em que trabalha: "Na minha época, quando me formei, tinha muita coisa de bancada, hoje é tudo automatizado, só tem equipamentos que você não sabe mexer". O técnico Tı8 também relatou que teve dificuldade na utilização dos equipamentos e sugeriu que fosse inserida no curso uma disciplina relacionada às novas tecnologias e os fundamentos técnicos que embasam os principais equipamentos da área de biodiagnóstico.

O processo de trabalho na área de laboratório em biodiagnóstico possui muito ainda do modelo taylorista-fordista, caracterizado principalmente pela fragmentação das funções, pela separação entre elaboração e execução. A maioria dos laboratórios de análises clínicas ainda segue essa lógica, nos quais o organograma extremamente hierarquizado determina as atividades que o técnico pode desempenhar, geralmente supervisionado por um gerente ou gestor. Entretanto, a maioria dos técnicos (66\%) respondeu que trabalha em um setor específico e conhece com profundidade apenas as tarefas relativas a esse setor, $34 \%$ dos técnicos trabalham seguindo um rodízio baseado principalmente no trabalho em equipe. Contrapondo a isso, de acordo com Loch (2015), tendo-se em vista a complexidade da saúde, as áreas não devem estar restritas aos seus problemas específicos, e sim estar inseridas em uma abordagem mais ampla. Assim, o conhecimento não deve ser isolado, mas integrado, a fim de que se tenha um olhar ampliado da saúde.

De modo mais detalhado, os resultados mostraram que na Instituição A quase todos os técnicos diversificam as suas atividades, apesar de atuarem em setores específicos, com exceção dos pertencentes ao setor da coleta e de virologia. Na Instituição $B$ todos os técnicos atuam em um setor específico sem diversificar suas atividades, fazendo as mesmas técnicas todos os dias. Na Instituição C, como se trata de um laboratório menor, todos os técnicos se revezam para executar as suas atividades em diferentes setores. Peduzzi (2003) salienta que as mudanças do mundo do trabalho industrial falam de uma tendência à atenuação da divisão do trabalho, porém, na área da Saúde, estudos mostram que o avanço tecnológico na área intensificou a divisão do trabalho. 

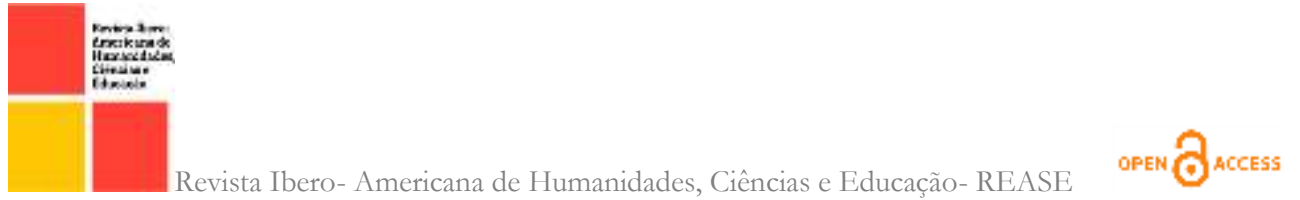

$\mathrm{Na}$ pesquisa desenvolvida por Teixeira (2003), a autora constata que no laboratório de desenvolvimento de vacinas virais pesquisado não existe rodízio ou escala na rotina do laboratório, as tarefas são distribuídas entre os funcionários, cabendo a cada um deles um fragmento da totalidade do trabalho.

Com a tese da "especialização flexível" surge uma nova forma de produção que articula desenvolvimento tecnológico e uma desconcentração produtiva, entretanto, os resultados mostram que em laboratórios de diagnóstico esse modelo encontra como obstáculo, a especificidade de cada área, que dificulta ao técnico dominar todas as tecnologias desta área. Um exemplo desse aspecto foi evidenciado na resposta de Ti8, o qual aponta um rodízio, mas delimita a área (Hematologia, Bioquímica e Imunologia).

Nesse ponto da categoria processo de trabalho, pode-se discutir a questão de estudo sobre as áreas do trabalho laboratorial em que estão sendo observadas mudanças tecnológicas que modifiquem as técnicas clássicas de diagnóstico. Na Bioquímica e na Urinálise, quase todas as técnicas clássicas feitas em bancada foram substituídas por equipamentos automatizados (apenas na Instituição $C$ a técnica para detecção de elementos anormais de sedimentação (EAS) ainda não está automatizado). Na pergunta da entrevista, referente às mudanças tecnológicas ocorridas no laboratório, $\mathrm{T}_{13}$ responde:

"A hematologia tem uma parte dela que está automatizada, no caso as que eu desenvolvo[...] a urinálise é automatizada. Na microbiologia nós até tínhamos o ATB que fazia leitura, mas é uma coisa que eles estão tirando porque acaba não sendo tão automatizada assim porque às vezes tem que se tirar outros processos, devido à dificuldade de[...] tipo assim... a bactéria ela aparece de um jeito ai daqui a pouco ela já está se modificando."

Teixeira e Murito (2007), afirmam que essas mudanças tecnológicas no processo de trabalho vêm atender os critérios de qualidade das atividades padronizadas (rastreabilidade e repetibilidade), além de permitir maior quantidade de exames por dia, uma vez que substitui o trabalho individual do técnico analisando cada amostra, por um aumento de exames sendo avaliado ao mesmo tempo por um equipamento. $\mathrm{O}$ avanço tecnológico influencia a profissão do técnico em análises clínicas, uma vez que promove um impacto no processo de trabalho com o aumento da velocidade e precisão dos 

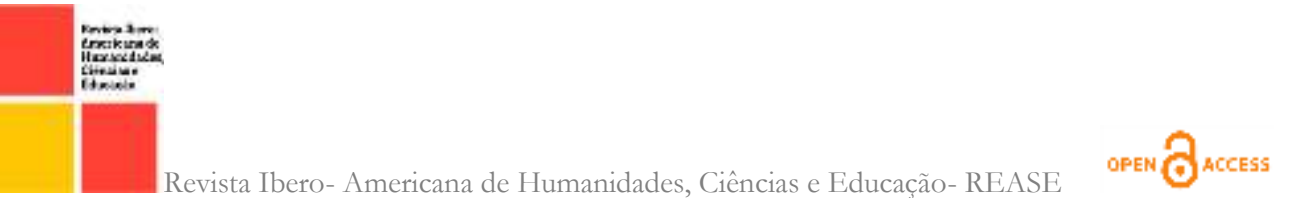

resultados obtidos (VELOSO; PAIXÃO, 2013). Porém, Murito (2007), argumenta que a introdução de novas tecnologias não reduziu as tarefas diárias do laboratório, uma vez que determinadas atividades não podem ser executadas pela máquina. A Inserção de novos equipamentos exige: validação, aferição, calibração, preparo de soluções, confecção de Procedimentos Operacionais Padrão, limpeza e assepsia do maquinário e dos materiais de apoio. Para o técnico, além de uma qualificação específica para a realização dessas atividades, essas mudanças acarretam novas demandas como, por exemplo, o conhecimento tácito que, segundo Machado (1996), trata-se de um saberfazer complementar e necessário ao sistema técnico (MACHADO, 1996). Graças a isso, ele introduz modificações nos processos reais de trabalho, condutas e soluções diferentes das prescritas para dar conta das variações, descontinuidades, diferenças de situações, imprevistos, no sentido de unir o que a divisão do trabalho separou: concepção e execução e as diversas etapas da execução.

"Sempre tem acontecido, sempre tem ocorrido assim uma mudança, por exemplo, a minha vida inteira eu trabalhei com urinálise e ai tipo assim, sempre tinha aquela fitinha e uma coisa assim, ai depois veio aquela química seca não é, você coloca ele ali dentro do aparelho e a gente nem sabe realmente o que acontece..." ( $\left.\mathrm{T}_{13}\right)$.

Quanto à categoria relativa às novas tecnologias um dos aspectos relacionados é a especialização no âmbito de que cada atividade desempenhada possui um conjunto de conhecimentos que se articulam, tornando o trabalho mais complexo, de tal forma, que o trabalhador se torna um especialista no setor que atua. Essas se referem, principalmente, aos setores de análises clínicas que utilizam técnicas de Reação em Cadeia da Polimerase (PCR) e de Biologia Molecular. Alguns trabalhadores ressaltaram a importância de conhecimentos relacionados à Biologia Molecular, devido às vantagens de serem implementadas formas de reduzir custos e diminuir o processo de trabalho.

Foi verificado que o setor de Virologia da Instituição A utiliza as referidas técnicas na sua rotina de trabalho. Segundo $\mathrm{T}_{7}$, "tudo sempre foi molecular", essa fala remete ao estranhamento da palavra sempre, por ser uma tecnologia relativamente nova. Analisando a documentação do referido setor, identificamos que este tem utilizado essa metodologia há aproximadamente cinco anos. Entretanto, nos outros 

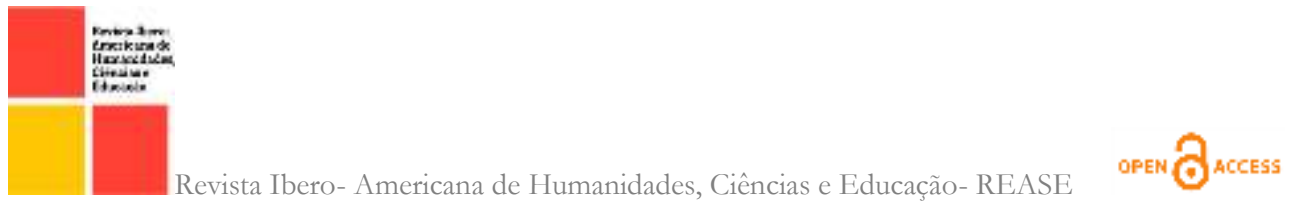

setores, das diferentes Instituições estudadas, nenhuma técnica clássica de rotina foi substituída pelo diagnóstico molecular.

Em relação ao impacto que o novo contexto de produção automatizada, focado em técnicas de biologia molecular, provoca no trabalho do técnico de laboratório em Análises clínicas, os resultados apontaram que apenas um setor entre os dezoito estudados apresentou esse tipo de técnica, totalmente implantada.

No setor de Parasitologia, segundo as respostas dos técnicos entrevistados (T5 e TI2), todas as técnicas continuam a ser feitas como há 30 anos, como, por exemplo, Método de Bearman, Faust, Kato-Katz, que continuam sendo utilizadas para o diagnóstico parasitológico, identificando larvas de nematódeos, cistos de protozoários e ovos de helmintos, respectivamente.

Nesta perspectiva, os resultados das entrevistas apontam que o único setor que apresentou mudanças tecnológicas significativas na área de biologia molecular foi o de Virologia, da Instituição $\mathrm{A}$, o que nos leva à complementação desse questionamento em relação à formação deste trabalhador. $O$ técnico $\mathrm{T}_{7}$ é graduado em física com especialidade em Boas Práticas de Laboratório e Biossegurança, além de ter feito curso técnico em Análises Clínicas.

"Na época foi uma virada porque eu trabalhava com metalúrgica e passei a trabalhar com saúde. [...]. Você trabalhar com metalúrgica a sua postura é um pouquinho mais grosseira, quando você trabalha com saúde você passa a ater uma sintonia fina um pouco mais regulada. Não que você não trabalhe com sensibilidade com medidas muito precisas em metalúrgica, então você precisa também, porque trabalha com engrenagem a coisa tem que ser muito certinha, mas a forma de você operar a coisa ela se torna um pouquinho mais minuciosa, então você passa a ser um pouquinho mais minucioso." $\left(\mathrm{T}_{7}\right)$

$\mathrm{Na}$ fala de $\mathrm{T}_{7}$ fica claro como ele levava a sério o seu trabalho. Ele exige de si mesmo novas atitudes em relação à área da saúde. A sintonia fina citada pelo técnico diz respeito às técnicas de biologia molecular onde são utilizadas micropipetas para diferentes diluições que precisam de muito cuidado para a precisão do método. Além disso, $T_{7}$ cita em suas respostas a necessidade de fazer cursos de atualização, uma vez 

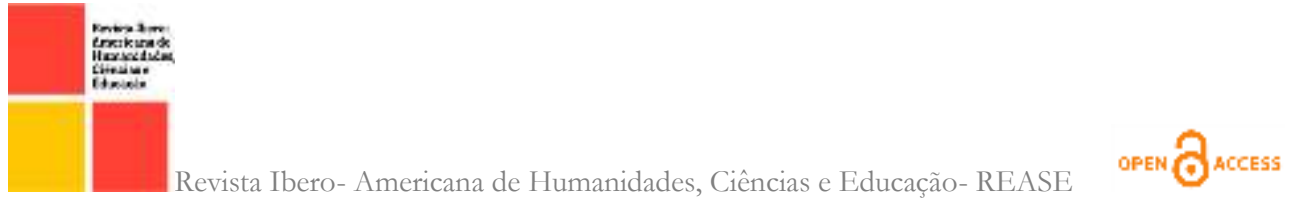

que, segundo ele, "muitas técnicas avançaram muito e, no meu caso, precisei ser capacitado porque me formei em I993".

Além da Virologia, os setores de Imunologia, Micologia e Microbiologia estavam presentes em apenas uma das Instituições pesquisadas (A ou B). A Instituição A é mais "completa” na área de diagnóstico de Doenças Infecciosas, a qual abrange os setores de Imunologia, Micologia, Virologia e Bacteriologia (não pesquisado). A pesquisa realizada nas instituições de referência, como a Instituição $A$, são extremamente importantes, pois essas são responsáveis pelo desenvolvimento das técnicas que serão empregadas em outros laboratórios clínicos de rotina.

Em relação aos equipamentos, 2 dos 18 técnicos entrevistados (II\%) consideraram que esses não estão adequados para a rotina de trabalho, mas relataram que não podem ser substituídos por equipamentos mais modernos, principalmente devido à burocracia para a compra. Em oito dos laboratórios estudados (44\%) houve a incorporação de novas tecnologias, mas apenas no setor de Virologia, como já mencionado, houve a substituição de técnicas tradicionais pela biologia molecular. Peduzzi (2003) relata que a incorporação das novas tecnologias na área da Saúde se faz de forma desigual, acontecendo principalmente nas Instituições públicas e privadas de médio e grande porte. Essa afirmação corrobora com os resultados encontrados nessa pesquisa, onde a Instituição $\mathrm{C}$, considerada de pequeno porte, não apresentou nos últimos anos mudanças tecnológicas significativas na área de diagnóstico clínico.

Os i8 técnicos entrevistados relataram que as metodologias passíveis de automação ainda não foram substituídas pelas automatizadas devido principalmente à relação custo/benefício, onde o número de exames realizados não é suficiente para justificar a aquisição de novos equipamentos.

Com o advento de novas tecnologias, o trabalho automatizado exige um novo perfil do técnico de laboratório, que pode transformá-lo num mero expectador com a função de apertar botões. No entanto, a maioria dos técnicos relatou que seria capaz de voltar para a bancada. Apenas, 2 dos 18 entrevistados responderam que não saberiam realizar as técnicas de modo não automatizado. 

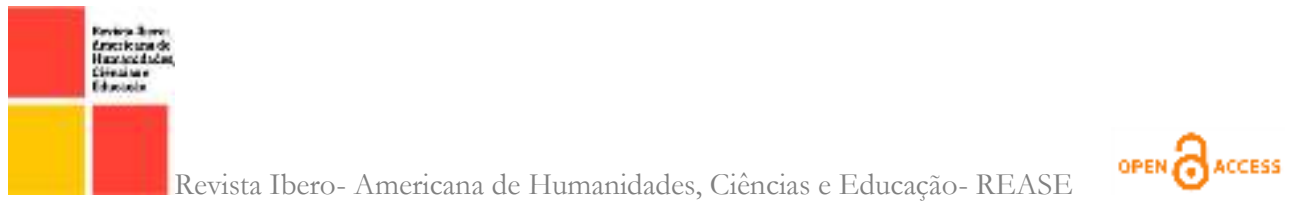

Pinto (2007) destaca que a produção, uma vez conduzida pela demanda, frente a um significativo desenvolvimento tecnológico, leva à necessidade de um trabalhador polivalente e multifuncional, com dimensões mais qualificadas e intelectuais para o trabalho e a diminuição do tempo de trabalho necessário para a produção. Isso é ratificado pela fala dos técnicos que listam, além das atividades técnicas executadas, novas demandas exigidas pela automação, como aferição e calibração do maquinário, conhecimento de inglês para leitura de catálogos e manuais e confecção de Procedimentos Operacionais Padronizados (POPs) para os equipamentos e atividades executadas no laboratório. Com isso, de acordo com Peduzzi (2003), há tendência a uma qualificação maior dos trabalhadores.

Quando há problemas de ordem técnica, $50 \%$ dos técnicos $(n=9)$ informaram que toda equipe é capaz de buscar as soluções, mas para 5(28\%), o problema deve ser resolvido pelo gestor e para 4 (22\%), pelo técnico no equipamento. E quando há dificuldade para a utilização dos equipamentos, $50 \%(n=9)$ se reporta ao gestor e os outros 50\% ( $n=9)$ ao técnico mais experiente. De acordo com a fala dos técnicos, quando há um erro na execução de alguma técnica, o procedimento é repetido e em alguns casos são observados os reagentes e é revisado o protocolo.

A grande demanda de análise da maioria dos laboratórios estudados gera a necessidade de maior agilidade para a liberação dos laudos, ou seja, maior rapidez na realização das técnicas. Este é portando, um campo de observação privilegiado no que concerne às mudanças tecnológicas na área de diagnóstico laboratorial em saúde, pois permite um estudo do perfil dos trabalhadores que estão sendo admitidos e do comportamento do mundo do trabalho.

\section{CONSIDERAÇÕES FINAIS}

A análise do processo de trabalho na área de biodiagnóstico nos locais pesquisados mostrou que nos setores de Bioquímica e Uroanálise todas as técnicas clássicas, antes desenvolvidas em bancadas, foram automatizadas. Esse fato, segundo os resultados obtidos, mostrou que houve um descompasso entre a formação do técnico que aprende as técnicas clássicas e sua prática profissional. Existe, portanto, uma 
necessidade de cursos de atualização nessa área que articulem os princípios das técnicas com as inovações tecnológicas.

O setor de Parasitologia, apesar de ter técnicas rotineiras e consideradas não tão complexas, não é passível de automação em curto prazo, uma vez que não há um interesse concreto por parte das empresas no desenvolvimento de equipamentos automatizados para o diagnóstico parasitológico. Essas doenças infecciosas são mais frequentes nos países em desenvolvimento, principalmente na população menos favorecida economicamente.

De um modo geral, nos outros setores estudados, nenhuma técnica clássica de rotina foi substituída pelo diagnóstico molecular, apenas o setor de Virologia da Instituição A emprega as técnicas de biologia molecular como PCR, principalmente na área de pesquisa, por ser um centro de referência nesta área. Esse resultado aponta que não houve nenhum impacto na área nem na formação do técnico que trabalha na área de Diagnóstico Clínico de rotina. Entretanto, consideramos importante que os conteúdos relativos às novas tecnologias em ambientes de análises clínicas sejam inseridos no curso de formação desse trabalhador para permitir, inclusive, que ele possa ampliar seus conhecimentos e que possa migrar nos diferentes setores da área de Saúde, incluindo a pesquisa, desenvolvimento tecnológico e controle de qualidade.

\section{REFERÊNCIAS}

BRASIL. Ministério da Educação. Secretaria de Educação Média e tecnológica. Educação Profissional: referenciais curriculares nacionais da educação profissional de nível técnico. Brasília: Ministério da Educação, 2000.

BRASIL. Ministério da Educação. Catálogo Nacional de Cursos Técnicos. Brasília: Ministério da Educação, 2020. http://cnct.mec.gov.br/, acessado em: 19/05/2021 às 15 horas.

BIANCHETTI, Lucídio. Da chave de fenda ao Laptop: tecnologia digital e novas qualificações: desafios à educação. Petrópolis/Florianópolis: Vozes, Santa Catarina: Ed. da UFSC, 2001. 

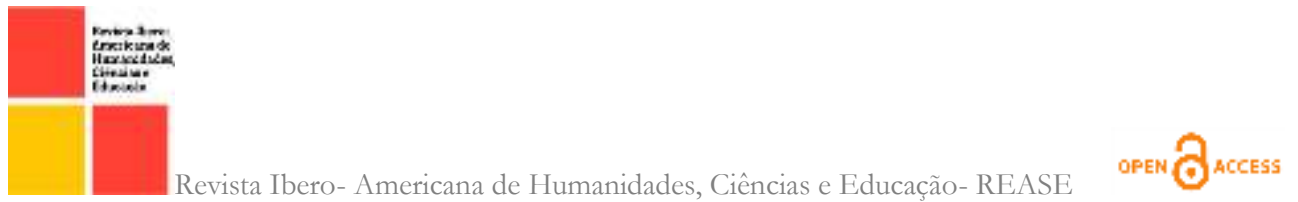

COSTA, Marco Antonio Ferreira da; COSTA, Maria de Fátima Barrozo da. Projeto de pesquisa: entenda e faça. 6. Edição. Petrópolis: Vozes, 2020.

DIAS NETTO, João Paulo Sobral. Automação laboratorial e a formação do técnico polivalente. Monografia de conclusão (Curso técnico de nível médio). Rio de Janeiro, Escola Politécnica de Saúde Joaquim Venâncio, Fiocruz, 200I.

FERRETTI, Celso João. Considerações Sobre a apropriação das noções de qualificação profissional pelos estudos a respeito das relações entre trabalho e educação. Educação e Sociedade, Campinas, v.25, n. 87, p. 401-422, maio/ ago. 2004 .

LOCH, Mathias Roberto. A promoção da saúde e a formação inicial do profissional de saúde: desafio e possibilidades. Saúde Meio Ambiente, Revista Interdisciplinar, Santa Catarina, v. 4, n.I, p.3-16, Jan./Jun., 2015.

LUDKE, Menga; ANDRÉ, Marli Elisa Dalmazo Afonso. Pesquisa em educação: abordagens qualitativas. São Paulo: EPU,1986.

MACHADO, Lucília Regina de Souza. Qualificação do trabalho e relações sociais. In:

FIDALGO, Fernando (Org.). Gestão do trabalho e formação do trabalhador. Belo Horizonte: Movimento de cultura marxista; 1996. p. 12-40.

MANACORDA, Mario Alighiero. Marx e a pedagogia moderna. São Paulo: Cortez, 2000.

MINAYO, Maria Cecília de Souza. O desafio do conhecimento: pesquisa qualitativa em saúde. São Paulo: Hucitec, 2000.

MONTEGUTI, B.R.; DIEHL, E.E. O ensino de farmácia no sul do Brasil: preparando farmacêuticos para o Sistema Único de Saúde. Trabalho, Educação e Saúde, v.I4, n.I, Rio de Janeiro, p. 77-95, Jan./Mar. 2016.

MURITO, Mônica Mendes Caminha. A análise, a organização do trabalho e as estratégias de qualificação no Laboratório de Saúde Pública Noel Nutels, Dissertação (Mestrado em Ensino em Biociências e Saúde) - Rio de Janeiro. Instituto Oswaldo Cruz/ Fiocruz, 2007. 
OLIVEIRA, Maria Beatriz Siqueira campos. Currículo por competências. Os desafios de sua implantação. Dissertação (Mestrado em Educação) - Rio de Janeiro. Universidade Estácio de Sá, 2005.

PEDUZZI, Marina. Mudanças Tecnológicas e seu impacto no Processo de Trabalho em Saúde. Revista Trabalho, Educação e Saúde, Rio de Janeiro, v. I, n. I, p. 75 -91, 2003.

PINHÃO, F.; MARTINS, I. Diferentes abordagens sobre o tema Saúde e Ambiente: desafios para o ensino de ciências. Ciência \& Educação, v. I8, n. 4, p. 819-835, 2012 PINTO, Geraldo. A organização do trabalho no século XX. Taylorismo, fordismo, Toyotismo. São Paulo: Editora Expressão Popular, 2007.

RIBEIRO, Victória Maria Brant. Discutindo o conceito de inovação curricular na formação dos profissionais de saúde: o longo caminho para as transformações no ensino médio. Revista Trabalho, Educação e Saúde, Rio de Janeiro, v. 3, n. I, p. 91- I21, 2005.

SILVA, Ana Lúcia abrahão. Educação profissional e gestão em Saúde: pressupostos teórico-conceituais na formação de profissionais de nível médio. Revista Trabalho, Educação e Saúde, Rio de Janeiro, v. 3, n. 2, p. 351-369, 2005.

TEIXEIRA, Márcia de Oliveira. Sobre o trabalho técnico em laboratórios de P\&D em saúde: apontamentos para a educação profissional. Revista Trabalho, Educação e Saúde, Rio de Janeiro, v. I, n. 2, p. III- 136, 2003.

TEIXEIRA, Márcia de Oliveira, MURITO, Mônica Mendes Caminha. Técnicos em laboratório de pesquisa em saúde e o trabalho na contemporaneidade: prolegômenos de um trabalho(ador) sob a neblina. Revista Trabalho, Educação e Saúde, Rio de Janeiro, v. 5, n.I, p. 79-I0I, mar. 2007 .

TURATO, Egberto Ribeiro. Tratado da metodologia da pesquisa clínico-qualitativa. Petrópolis: Vozes, 2003.

VELOSO, Bianca R.; PAIXÃO, Flavio Henrique Marcolino da. Processo de qualificação dos técnicos em análises clínicas no Brasil: primeiras aproximações. In: MOROSINI, Márcia Valéria Guimarães Cardoso et al. (Org.). Trabalhadores técnicos em saúde: aspectos da qualificação profissional no SUS. Rio de Janeiro: EPSJV, 2013. p. 295-334. 